\title{
Testing for consensus on Kyrgyz rangelands: local perceptions in Naryn oblast
}

\author{
Jordan Levine $^{1}$, Aiganysh Isaeva ${ }^{2}$, Hisham Zerriffi $^{3}$, Ian M. S. Eddy $^{4}$, Marc Foggin $^{2,5}$, Sarah E. Gergel ${ }^{4}$ and Shannon M. Hagerman $^{3}$
}

\begin{abstract}
Consensus on the state of rangelands is often elusive. This is especially true in the primarily agropastoral former Soviet republic of Kyrgyzstan. Some argue Kyrgyz rangeland is being rapidly degraded by overgrazing. However, poor data and climatic changes confound this assessment. Thus there is contention amongst researchers, state officials, and local agropastoralists about the etiology and appropriate degree of concern regarding changes in flora and landscape patterns. This lack of consensus makes pasture management difficult for local elected managers. In this study, we use audiovisual primes, structured interview tasks, and consensus analysis to examine the degree of agreement among local agropastoralists of Naryn oblast about (a) the nature of several degradationambiguous plant and landscape types found in the area, and (b) indicators of "good" pasture. We find relatively little interparticipant agreement on high-resolution details, but a pattern of consensus regarding (i) a refutation of select species as indicators of degradation, as well as (ii) apparent shared heuristics for determining what makes for good, versus bad, pasture. We consider socio-historical and cognitive drivers of these patterns, and close with a discussion of implications for management.
\end{abstract}

Key Words: Central Asia; consensus analysis; degradation; herding; Kyrgyzstan; local perceptions; management; pastoralism; post-Soviet

\section{INTRODUCTION}

Kyrgyzstan is a small post-Soviet Central Asian republic, consisting largely of rangeland. Its economy is highly dependent on pastoralism, mainly sheep and cattle (Dörre and Borchardt 2012). Since the Soviet collapse, the government has been struggling to reconstitute a functioning agro-pastoral management system (Farrington 2005, Bichsel et al. 2010). After several failed state-administered pasture-use policies, a new law was introduced in 2009 that nominally devolved pasture management to the local level (Crewett 2012, Shigaeva et al. 2016).

This 2009 system (modified again in 2011) is the product of a new policy consensus, inspired directly by Ostrom (1990). The intent is to privilege local self-organization over top-down state dictates (Crewett 2012). Under the new system, local pasture user associations (PUAs) each elect a pasture committee (PC), headed by a pasture manager (PM), whose salary is paid by the state. (PUAs and their PCs consist of pasture users who live within local administrative boundaries known as "rayons," situated within regions called "oblasts").

Together, the PM and PC are primarily responsible for (a) collecting pasture use fees from all the pasture users within the rayon; (b) determining and enforcing which pastures within the rayon are to be used, how intensively, by whom, over what periods of time; and (c) dispute resolution (Dörre 2015). The overall charge of the PM and PC is to enable users to sustainably maximize livestock productivity, while minimizing long-term degradation of the rangelands under their administration.

Thus far, this system has had only limited-to-mixed success (Kerven et al. 2011, Crewett 2015, Dörre 2015). Many pasture users remain either skeptical or simply unaware of the new arrangement, while some claim it has been counterproductive
(Mestre et al. 2013, Shigaeva et al. 2016). To date, researchers have documented at least three key issues limiting the effectiveness of the system. The first of these is the widespread breakdown of Soviet-era infrastructure, which creates inherent limits to flock mobility (Crewett 2012). This means that even if a PM wants a given herder to leave a given pasture and migrate to another, the physical or economic means to do so may not exist. A second, related limiting factor is the lack of effective enforcement mechanisms (Mestre et al. 2013).

A third, less tangible but no less important, issue is an apparent lack of consensus amongst pasture managers, pasture users, and academically trained state and international experts, on just how much pasture is "degraded," let alone what "degraded" pasture even is, and how to recognize it (Liechti 2012, Levine et al. 2017). Without shared definitions, and shared mental models, effective self-organized collaboration can be difficult (Standifer and Bluedorn 2006).

Levine et al. (2017) and Liechti (2012) have published initial qualitative findings on how and why there is such low apparent consensus on degradation amongst academically trained experts and locals. One clear proximate cause is disparate, self-serving interpretations of the oft-invoked Soviet-era Russian term for rangeland degradation, "деградация / degradatsiya" (Levine et al. 2017).

A second, more fundamental driver of the apparent gap in perceptions amongst academics, managers, and locals is the fallout of the Soviet collectivization process. During the Soviet era, traditional pastoral livelihoods, and their concomitant, informal pasture use arrangements, were radically disrupted. Many rural Kyrgyz were reassigned to agricultural work in collectivized farms (sovkhoz and kolkhoz), while others were assigned to shepherd livestock according to the centrally

${ }^{1}$ Liu Institute for Global Issues, University of British Columbia, Vancouver, Canada, ${ }^{2}$ Mountain Societies Research Institute, University of Central Asia, Bishkek, Kyrgyzstan, ${ }^{3}$ Department of Forest Resources Management, University of British Columbia, Vancouver, Canada, ${ }^{4}$ Department of Forest and Conservation Sciences, University of British Columbia, Vancouver, Canada, ${ }^{5}$ Institute of Asian Research, University of British Columbia, Vancouver, Canada 
commanded optimization calculations of urban experts (Farrington 2005). Herders were thus detached from the decisionmaking processes surrounding how to manage the long-term sustainability of pastures (Rahimon 2012).

During Soviet rule, Kyrgyz pasture was also subsidized with intensive fertilizer and pesticide inputs (Rahimon 2012). Even lands that contemporary researchers would deem marginal, i.e., not suitable for sustained grazing, were, during the Soviet era, sometimes regarded as degraded, and merely in need of added inputs to become productive (Levine et al. 2017). These considerations fed into the wider Soviet decision-making apparatus, resulting in the construction of large amounts of transportation infrastructure, and the assignment of summer pasture to herders from often very distant rayons (Farrington 2005).

When the Soviet Union collapsed, the pasture management system collapsed with it. Crucially, the funding for chemical inputs, and for moving large volumes of livestock long distances, abruptly ended (Farrington 2005). Much of the transport infrastructure fell into disrepair (Farrington 2005). Yet, as the collective-farm system disintegrated, and many state-funded urban jobs evaporated, many Kyrgyz had to take up pastoralism to eke out a modicum of income and food security (Dörre and Borchardt 2012). Although the bulk of rural Kyrgyz's pre-Soviet ancestors were multigenerational pastoralists, many of today's rural Kyrgyz herders are at least a generation removed from the traditional pastoral lifestyle. As such, they are no longer engaged in the historical clan-based management and migration systems that were dissolved by Soviet collectivization (Farrington 2005).

\section{Ecological ambiguity and a dearth of data}

Although numerous publications describe a troubling downward trend in Kyrgyz rangeland quality, neither these trends, nor their etiology, are obvious at management-relevant spatial scales (Kerven et al. 2012). Rather, ambiguity and multifactorial considerations abound, while up-to-date, actionable data is limited both in quantity and quality (Robinson 2016).

Long-term, high-quality, remote-sensing, time-series data is a promising tool (Eddy et al. 2017), but is not always readily accessible at the local level. Meanwhile, as livestock load in Kyrgyzstan has begun to rebound from an initial post-Soviet decline, slow-moving climatic changes have also been affecting the region (Eddy et al. 2017). This makes definitively disentangling the etiology and relative severity of landscape change exceedingly difficult (Eddy et al. 2017).

Moreover, limited national budgets mean that local-scale vegetation surveys in Kyrgyzstan are rare (Hamidov et al. 2016). The variety and pastoral uses of most endemic flora are welldocumented (UCA 2011, Flermoneca 2015). However, when our team began work in the region in 2015 , there was contention and confusion amongst academic experts, PMs, and pasture users, over which plants constitute indicators of degradation by overgrazing, versus natural artifacts either of Kyrgyzstan's varied terrain, or of other confounding processes (Liechti 2012, Hoppe et al. 2016). Below, we provide some brief context on the study site, followed by an outline of our core research aims.

\section{Naryn Oblast, Kyrgyzstan}

Naryn is a high-elevation oblast (administrative region) in central Kyrgyzstan (see Fig. 1), straddling the slopes of the central Tian Shan mountain range, and endowed with extensive pastures that cover more than $60 \%$ of the land area (Kulov 2007). Despite this volume of pasture, the continental climate and short growing season leave much of the land area inhospitable to livestock outside of summer (Kreutzmann 2012). Following a livelihood pattern known as transhumance, herders lead their flocks (often composed partially of fellow village dwellers' livestock) slowly uphill while the snow retreats, grazing pastures composed largely of Artemisia and Festuca spp., eventually reaching verdant valleys as high as 4000 meters (Imanberdieva 2015). Herders summer in these valleys in small family units, living in yurts, drawing water and, when possible, firewood from the surrounding landscape, while the animals fatten (see Fig. 2). In the autumn, herders and their families return with their flocks to farms and villages at lower elevations. There, the livestock, primarily sheep, but also horses, cows, goats, and yaks, are returned to their sedentary owners, and pass the winter subsisting on fodder (Mudahar 1998).

Fig. 1. Kyrgyzstan and study region.

\section{The Kyrgyz Republic}

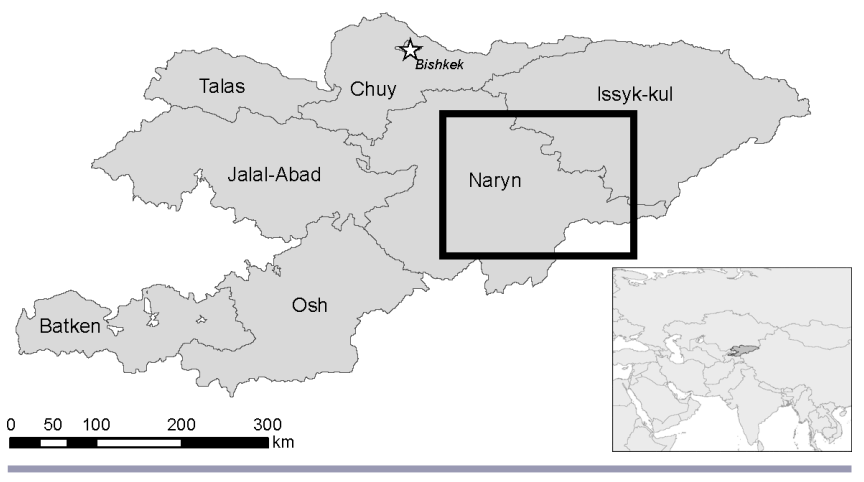

Fig. 2. High summer pasture in Naryn oblast.

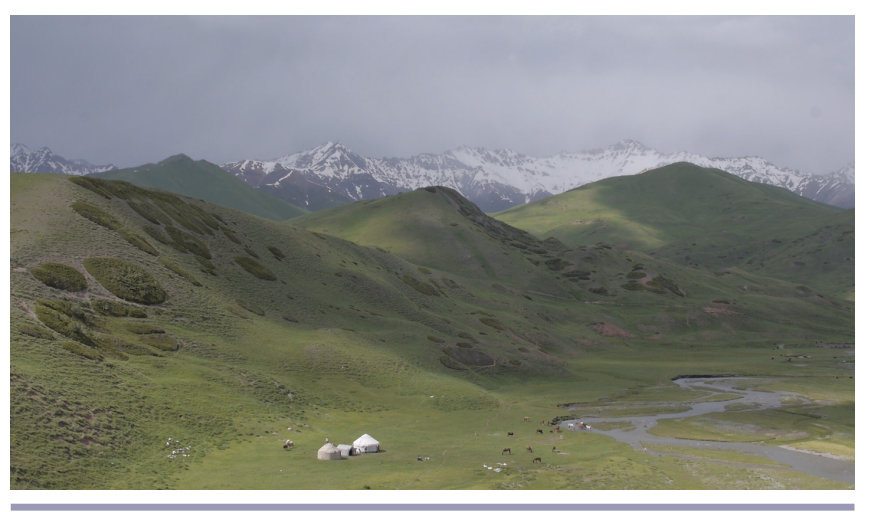

Pockets of coniferous forest exist at higher elevations in Naryn, while below 2000 meters the land is exceedingly arid. Climate change is also of imminent concern: warming trends in winter and summer have had a visible impact on the region's glaciers 
(Gan et al. 2015), which constitute a primary source of potable water for herders and their flocks.

\section{Research aims}

Ongoing climate change, de-development, herd resurgence, and a dearth of reliable data, have together made it difficult for PCs and PMs to make management decisions that are simultaneously scientifically sound, and well accepted by their pasture users. PCs and PMs need more reliable data about the more ambiguous features of their assigned terrain (Eddy et al. 2017). They also need a clearer understanding of how their pasture users perceive and make decisions on the landscape (e.g., Levine et al. 2017).

Given these management needs, in the summer of 2015, we began fieldwork in Naryn oblast to improve baseline knowledge of (a) the state of Naryn rangeland and (b) locals' perceptions of this rangeland, using a diversity of methods. We were especially curious about locals' perceptions regarding a specific subset of landscape-types, and plant species (see Methods), which earlier preliminary fieldwork in the region had shown anecdotally to be of contentious meaning for different actors in the country, i.e., state-trained ecologists, PMs, herders. Our summer 2015 efforts comprised a remote sensing component, a vegetation survey component, and both structured and open-ended interview components. The results of the former two methods are reported in Eddy et al. (2017), while the results of the open-ended interviews are reported in Levine et al. (2017). In this paper, we report on the methods and findings of the structured interview component.

The aim of our structured interviews was to gain baseline insights on the following two overarching research questions about local perceptions:

(R1) What do locals perceive as "good" pasture, and why? More specifically, to what degree do rural Naryn locals agree on the desirability and etiology of various types of rangeland in the region that present with ambiguous implications for pasture management?

(R2) To what degree do rural Naryn locals agree on the identity, desirability, and uses of several specific endemic plant species with ambiguous implications for pasture management, i.e., Dracocephalum integrifolium, Calamagrostis epigejos, Caragana pleiophylla, and Phlomoides oreophila?

A high, versus low, level of agreement amongst participants on the questions contained within $\mathrm{R} 1$ and $\mathrm{R} 2$ could point to the nature and degree of any shared social-ecological narrative, or common set of ecological perceptions, amongst locals. Revealing the level of consensus could (i) improve our understanding of pastoral decision making; and (ii) help managers craft more effective outreach strategies, i.e., for public engagement in effective pasture management.

\section{METHODS}

Our research included a series of one-on-one and small-group interviews amongst herders, farmers, and pasture committee members in Naryn oblast. All interviews were conducted in Kyrgyz. Herder and farmer participants were chosen based on their summer homes' proximity to high summer pasture sites that had been selected by ecologist colleagues for vegetation surveys (see Eddy 2016, Eddy et al. 2017). Pasture committee members were selected by job title and availability to meet. Interviews included (1) an image-sorting task aimed at ascertaining local perceptions of landscape quality, (2) an image-identification task aimed at ascertaining local perceptions of specific plant species, and (3) a free listing exercise on the desirable features of pasture, using a video prime (see details for each, below). Interview activities (1) and (3) addressed research question R1, while interview activity (2) addressed research question $\mathrm{R} 2$. In total, we formally interviewed 46 individuals (32 men, 14 women), including 30 herders, nine sedentary livestock-owners, and eight pasture committee members (one of whom was also a herder) Because participants tended to answer the image- and videobased tasks as family units, often involving discussion and ultimate consensus amongst all family members present, we collapsed those interviews by family, ultimately rendering $\mathrm{n}=37$ responses, aggregated by household, i.e., often dwellers of one to three yurts shared by one extended family. Of those 37 families, $\mathrm{n}=36$ completed the vegetation questions, while $\mathrm{n}=30$ completed the free list task. The interviews were audio recorded, and categorical and sorting data were entered into a spreadsheet, prior to subsequent analyses.

\section{Activity 1: landscape sortings}

In relation to our first broad research question (R1), our research team was uncertain as to the causes underlying the divergent appearance of several specific types of rangeland encountered in the Naryn region. We thus wished to ask locals for their input on these rangeland-types, and used this as subject matter with which to test R1. We also wanted to ascertain how locals reasoned about which kinds of pasture were best or worst for livestock, and if this matched our ecologist colleagues' assumptions. To answer these questions, we took color photographs of nine of these different kinds of rangeland within Naryn oblast (see Fig. 3). Each of these photographs (approximately $15 \mathrm{~cm} \times 20 \mathrm{~cm}$ ) was laminated and labelled with a single letter from A to I on the reverse side, for the interviewers' identification purposes. (The alphabetic ordering corresponded to what our field ecologist hypothesized would be the "best" (A) descending to the "worst" (I) rangelands for herding purposes.)

When interviewing families, we would shuffle these photos, then spread them out, face-up, in random order across the yurt floor or dining table. We would then ask the head of the household to physically organize and rank the images from "best" to "worst" pasture. (In practice, this, as with all subsequent tasks, was carried out by all family members present, as a group, but questions were directed at the head of the household for cultural reasons). This ranking task proved challenging, and in each of the first five families we interviewed, participants instead intuitively sorted the photographs into categories of "good," "medium," and "bad." We thus decided to use this emergent trifurcated sorting schema with all subsequent interviewees. Once a family had arrived at their final sorting, we recorded the results in a spreadsheet. We then asked the participants to describe (a) why they put each of the nine pictures into their respective categories; and (b) why they thought each of the nine landscapes looked the particular way they did, e.g., why some were drier, others greener, others rockier, and so on. All answers to these qualitative questions were both audio recorded and entered in note form in a spreadsheet for later review. 
Fig. 3. Landscape images and sortings arranged from highest to lowest degree of interparticipant agreement (measured by UCINET's weighted frequency function), grouped by household.

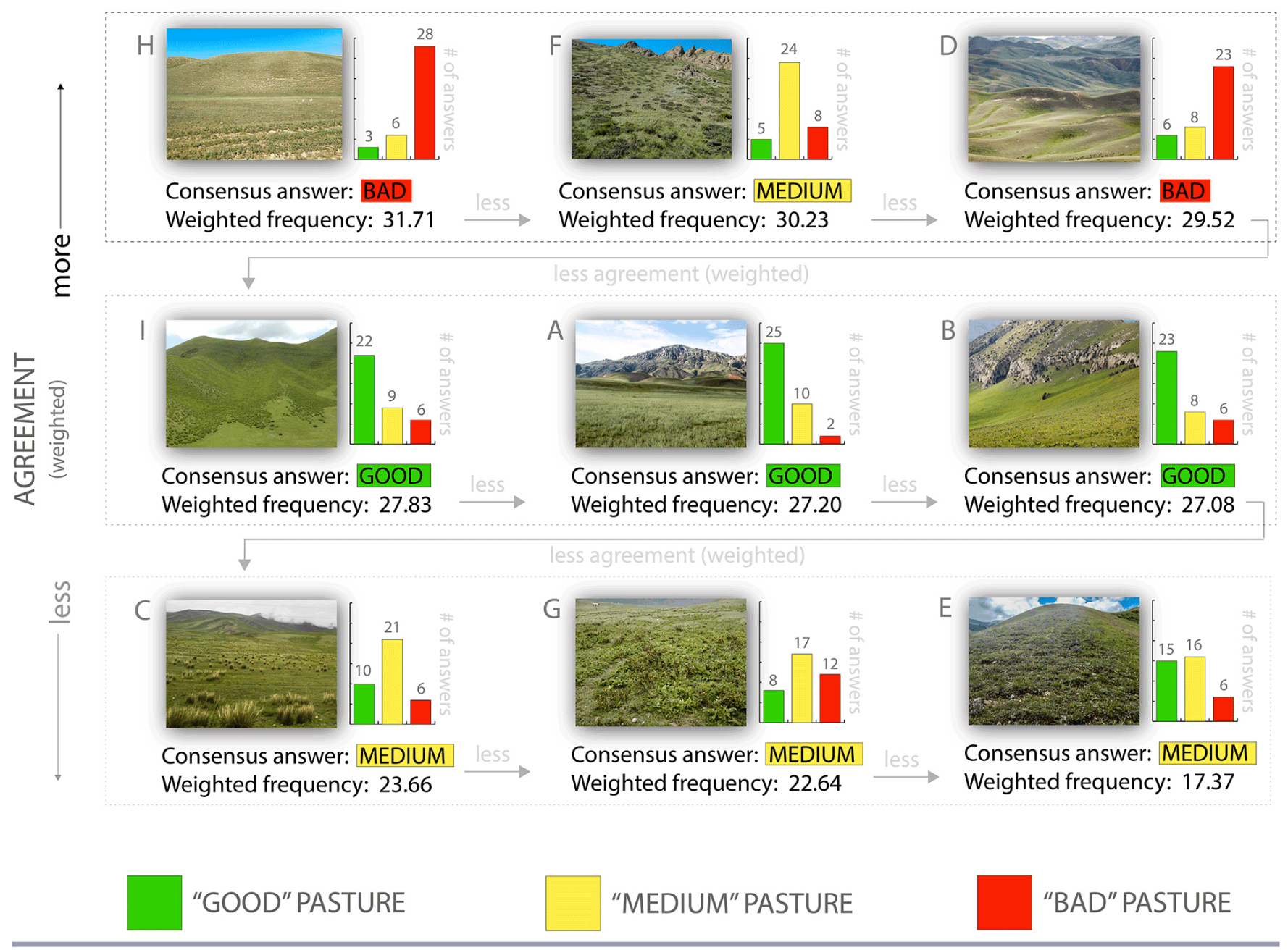

Later, we analyzed all categorical sorting data using the consensus analysis function of the freeware package UCINET 1.6 (Romney et al. 1986, Borgatti et al. 2002). Consensus analysis has been used to determine the existence and strength of shared perceptions within and across human samples in numerous social-ecological studies to date (e.g., Stone-Jovicich et al. 2011, Carothers et al. 2014). As applied to our study, we used UCINET to derive a measure of interhousehold agreement regarding the appropriate category for each of the nine landscapes. UCINET output takes the form of (i) a "culturally correct," meaning, most widely shared answer to each question; (ii) a "weighted frequency" score that provides a metric of interhousehold agreement on the culturally correct answer for each landscape; and (iii) an eigenvector ratio suggesting whether or not there is, indeed, one coherent "culture" of perceptions shared by all households in the context of the question set (Romney et al. 1986).

\section{Activity 2: vegetation questionnaire}

In relation to our second broad research question (R2), our team was also uncertain as to the perceived forage value of four specific native plant species observed in the region: Dracocephalum integrifolium ("A"), Calamagrostis epigejos ("B"), Caragana pleiophylla ("C"), and Phlomoides oreophila ("D"). To test local perceptions, and their degree of consensus, regarding these flora, we presented each family with laminated color photographs (approximately $20 \mathrm{~cm} \times 30 \mathrm{~cm}$ ) of the respective species in question (see Fig. 4). Each of the four photos was labelled with a letter (A to $\mathrm{D})$, on the reverse side, for interviewers' identification purposes.

As in the previous task, we would shuffle these photos, then spread them out, face-up, in random order across the yurt floor or dining table. The head of the household was then asked if he or she recognized any of the species depicted. As before, in practice, all family members present would participate in the exercise, often discussing the plant features and names amongst themselves. The name that the family settled on for each given species was then recorded. Subsequently, the head of the household was asked which kinds of livestock tend to eat which of the four identified species. We recorded the family's answers to this question for each of the five main Kyrgyz livestock species: sheep, goats, horses, cows, and yaks. We then asked the head of the household if each 
Fig. 4. Interparticipant agreement on edibility, degradation indicator status, and desirability of plants, grouped by household.
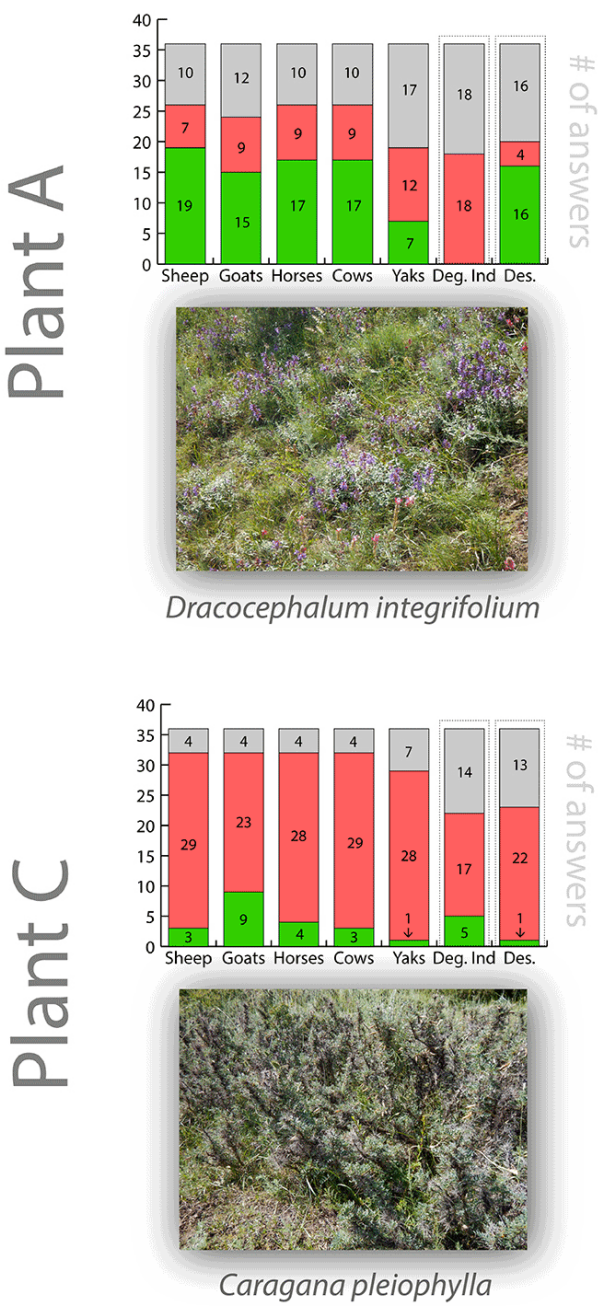

yes / eats

no / doesn't eat

don't know / no answer
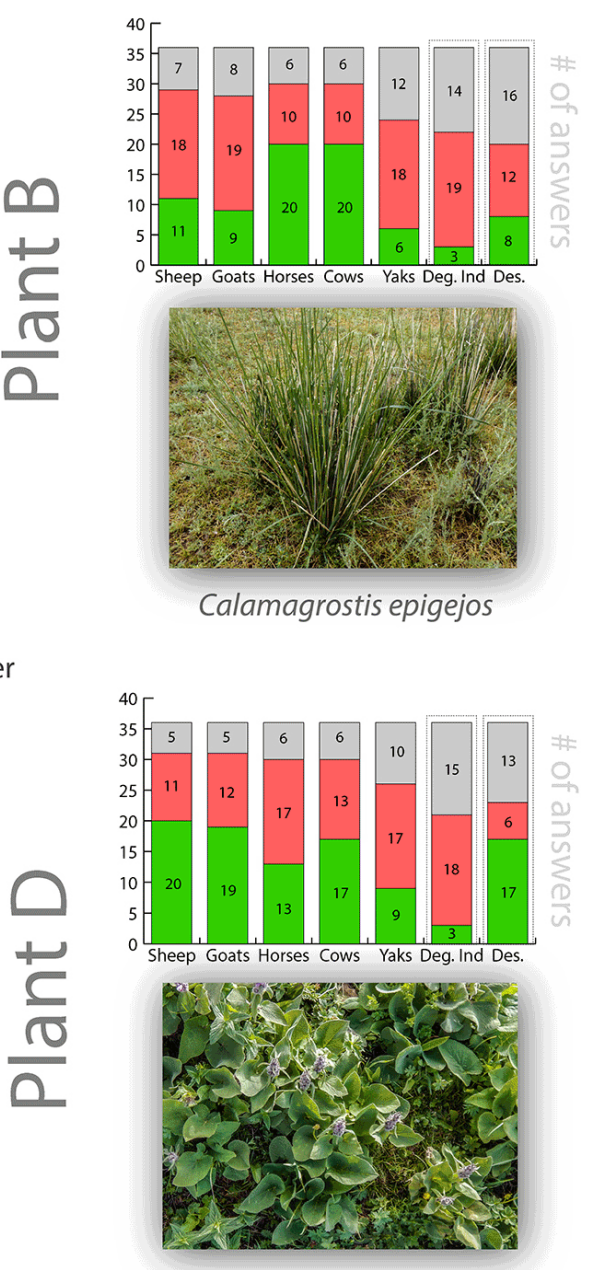

Phlomoides oreophila of the four plant species was an "indicator of [pasture] degradation" (using the oft-repeated Russian term, деградация / degradatsiya). We recorded the family's collective answer for each plant species. Finally, we asked whether each of the four plant species was "desirable to have in one's pasture." We recorded the family's answers to this question, as well. As with the Activity 1 data, we ultimately tallied these answers across all families, and used UCINET to analyze the degree of interhousehold consensus.

\section{Activity 3: free list of desirable pasture-site indicators}

In relation to $\mathrm{R} 1$, we also wished to elicit which factors locals considered the most important when choosing where to herd animals. Because this variety of knowledge is at least partially tacit (Ellen and Harris 2000), we wanted to devise a way that would first make such knowledge more cognitively accessible to participants. To do this, we video recorded multiple pastoral scenes that we encountered during a pilot visit to the field, i.e., footage of livestock grazing in various settings, with and without yurts visible (e.g., see Fig. 2). We edited these clips together into a single video of approximately two minutes in length. We then used this video during a priming exercise with each family, in which we would play the video on a tablet for everyone present in the household to see. We asked those present to collectively verbalize whatever it was they saw on the screen, as they were seeing it. For each family, we would leave the video playing on loop until participants had verbalized as much as they could of what they saw. Immediately subsequent to this priming task, we asked the head of the household to list the "things that make for a good pasture." These terms, and the order in which they were listed, were both audio recorded and entered into a spreadsheet. All listed terms were later summed across all families, producing a frequency list.

\section{RESULTS}

\section{Landscape sortings, R1-A, Activity 1}

The ratio of the largest to second-largest eigenvectors produced by the consensus analysis was $2.192: 1$. This is notably lower than $3: 1$, which is the standard benchmark in the literature for determining whether a participant pool shares a single "culture" regarding a given domain of knowledge (Romney et al. 1986, 
Borgatti et al. 2002). In other words, households' views on which of the presented landscapes were good, medium, or bad were fairly inconsistent with one another.

There was, nonetheless, some degree of interhousehold agreement. In Figure 3, we present each landscape in descending order of interhousehold agreement regarding its culturally "proper" categorization (as measured by UCINET's weighted frequency function).

Free list of desirable pasture-site indicators, R1-B, Activity 3 Although there was considerable disagreement amongst households regarding the landscape sortings, participants did tend to list a similar cluster of indicators of good pasture. Table 1 comprises two lists, one listing the frequency of ungrouped terms translated directly from the Kyrgyz (local species names in italics), and the second listing the frequency of terms grouped into overarching qualitative categories.

Table 1. Free list of desirable pasture-site indicators: results.

\begin{tabular}{|c|c|c|c|}
\hline \multicolumn{2}{|l|}{$\begin{array}{l}\text { Stated indicators of good } \\
\text { pasture (ungrouped) }\end{array}$} & \multicolumn{2}{|c|}{$\begin{array}{l}\text { Stated indicators of good pasture } \\
\text { (grouped) }\end{array}$} \\
\hline $\begin{array}{l}\text { Ordered by frequency of } \\
\text { mention }(n=30)\end{array}$ & & $\begin{array}{l}\text { Ordered by frequency of me } \\
(\mathrm{n}=30)\end{array}$ & ention \\
\hline Water (access) & 21 & Grass (presence \& quality) & 23 \\
\hline Grass (betege) & 15 & Water (access) & 21 \\
\hline Open space & 7 & Trees for wood & 16 \\
\hline Wood (access) & 6 & Open space (visibility) & 9 \\
\hline Flatness & 5 & Flatness & 5 \\
\hline Mountains & 4 & $\begin{array}{l}\text { Mountains \& glaciers } \\
\text { (proximity) }\end{array}$ & 5 \\
\hline Trees (general) & 4 & Good climate & 4 \\
\hline Trees (karagai) & 4 & Soil quality (salt content) & 3 \\
\hline Good climate & 3 & Diverse plant species & 3 \\
\hline Grass (height) & 3 & Animals gain weight & 2 \\
\hline $\begin{array}{l}\text { Soil quality (salt } \\
\text { content) }\end{array}$ & 3 & Accessibility & 2 \\
\hline Accessibility & 2 & Animals don’t stray & 1 \\
\hline Animals gain weight & 2 & Animals are satisfied & 1 \\
\hline Grass (color) & 2 & Enough shade & 1 \\
\hline Grass (nutritiousness) & 2 & No wolves & 1 \\
\hline Plant diversity & 2 & Not excessive elevation & 1 \\
\hline Visibility & 2 & Shelter from wind & 1 \\
\hline Air quality & 1 & & \\
\hline Animals don’t stray & 1 & & \\
\hline Animals are satisfied & 1 & & \\
\hline Enough shade & 1 & & \\
\hline Grass (growth speed) & 1 & & \\
\hline Near a glacier & 1 & & \\
\hline No wolves & 1 & & \\
\hline Not excessive elevation & 1 & & \\
\hline Shelter from wind & 1 & & \\
\hline $\begin{array}{l}\text { Artemisia tianshanica } \\
\text { (shibak) }\end{array}$ & 1 & & \\
\hline Trees (archa) & 1 & & \\
\hline Trees (kastonday) & 1 & & \\
\hline
\end{tabular}

\section{Vegetation questionnaire, R2, Activity 2}

As with the landscape sortings, there was considerable variation in families' answers to the vegetation questions (see Fig. 3). There was total consistency regarding the local names families gave for two of the four presented plant species: chii (plant B) and too kuiruk (plant C). Plant A was identified alternatively as shybak, bede, esparset, chirmo, shalba, and koko meren. Plant D was identified alternatively as shimur, shimek chop, and sormo chop. There was little agreement regarding which of those species were edible by which kinds of livestock. There was wide agreement specifically regarding the relative inedibility of $C$. pleiophylla (plant C) by any kind of livestock other than camels. One further point of agreement is that very few participants identified any of the four plants as "indicators of degradation."

\section{DISCUSSION}

Despite a relatively low degree of interhousehold agreement on answers to each of the three tasks (particularly the landscape sortings and vegetation questions), there is, we believe, a pattern in the collective results worthy of consideration.

In the landscape sorting task (Activity 1), the most interhousehold agreement (by weighted frequency) is seen on landscapes $\mathrm{H}, \mathrm{F}$, and $\mathrm{D}$. What $\mathrm{H}$ and $\mathrm{D}$ have in common is that they are drylooking; simply put, they are not very green compared to the other landscapes. Landscape $\mathrm{F}$ is green, but visibly contains large patches of $C$. pleiphylla (plant $\mathrm{C}$ ), the sole plant from the subsequent vegetation-identification task (Activity 2) that participants near universally described as "undesirable."

In the free listing task (Activity 3 ), the two most frequently cited indicators of good pasture were an abundance of good-quality grass, and the availability of water. It seems, then, that when judging the pastoral utility of a landscape, locals are particularly focused on these aspects, i.e., the greenness or presence of desirable grass species, and likely proximity to a water source. Thus, given landscapes H, F, and D epitomize the visual inverse of these indicators, participants found it easy to categorize them unfavorably relative to other landscapes shown.

The next three most consistently categorized landscapes (by weighted frequency) were I, A, and B, all of which were most frequently labelled "good" by participating families. This is consistent with the dominant indicators arising in the free listing task. Namely, landscapes I, A, and B, are all visibly green, suggesting both good-quality grass (or, at least, plant cover), and proximity to water. Notably, I, A, and B each feature two other indicators of desirable pasture that were mentioned relatively frequently in the free listing task: wide horizons and mountain peaks.

Landscape A is dominated largely by Artemisia tianshanica (locally, shibak), one grass species that was mentioned by name during the free listing task, specifically. Conversely, landscape I is dominated partially, although not entirely, by the dark-green $A$. dracunculus (common tarragon), which our state-trained Kyrgyz ecologist colleagues consider an indicator of degradation. Our results suggest, therefore, that the main indicators of concern for many participants, i.e., the presence of green ground cover, likely proximity to water, visibility, and proximity to mountains, trump the relevance of the particular vegetative makeup of the landscape. The inverse is true for our Kyrgyz ecologist colleagues.

From a cognitive perspective (Levine et al. 2015, Levine et al. 2017), this supports the notion that locals, versus academics and managers, have dramatically different aims when parsing the variegated, often ambiguous Kyrgyz landscape. They are employing different cognitive heuristics to make actionable meaning out of the environment (Liechti 2012, Levine et al. 2015; 
see Levine et al. 2017 for further elaboration on the likely roots of this cognitive divide).

Finally, the most divisive landscapes were C, G, and E. These landscapes were most frequently sorted into the "medium" category, although this is confounded by a particular lack of interhousehold agreement. All three of these landscapes contain multiple species of vegetation. Landscape $C$ features large clumps of C. epigejos (plant B). Landscapes $\mathrm{G}$ and $\mathrm{E}$ appear to be at least partially covered in P. oreophila (plant D), and/or D. integrifolium (plant A). In Figure 4, we present the low interhousehold agreement regarding the pastoral use and desirability of all three of these plant species, i.e., plants A, B, and D. This is despite their relative abundance in the wider study area (see Fig. 1; Eddy 2016, Hoppe et al. 2016).

Taken as a whole, the pattern of results suggests the following. Rural Kyrgyz in Naryn appear to have a shared set of visual heuristics for judging the pastoral desirability of a landscape. However, these heuristics (greenness, proximity to a water source, access to firewood, elevation, visibility) are relatively lowresolution, centered on the human scale, and revolve around the most pressing, practical needs of agropastoralists. The closer one focuses on knowledge about the uses of various plant species, and on the floristic composition of a given landscape, the less consensus one observes. Generally speaking, we did not find evidence of statistically culturally correct perceptions amongst Naryn households regarding the etiology, or usability, of the more ambiguous plant and rangeland-types that, in our experience, presently confound $\mathrm{PCs} / \mathrm{PMs}$ and academic researchers alike.

Collectively, these findings suggest several possibilities. One, is that our methods were simply ineffective at eliciting widely shared tacit knowledge that nonetheless does exist. It is possible, for instance, that the laminated photographs we presented were not tangible or visceral enough to cue participants' memories, while the video task (Activity 3 ) was more effective at doing so. It is also possible the particular landscapes that we photographed and presented were themselves so variegated in their potential etiologies that it is impossible to meaningfully discern their desirability as pasture beyond what the participants were able to do. If true, future research could experiment with refining this method by testing different kinds of audiovisual material, while holding the terrain or floristic content of the photographs and/ or videos relatively constant.

A second possibility may be one suggested by prior research: the geographical and social fragmentation wrought by the Soviet collectivization process altered patterns of rural Kyrgyz life to such a degree that once-common knowledge of subtle differences between certain plants and landscapes is no longer common (Wong 2018). It is possible that, relatively dissimilar to Altai Siberians' experience (Klubnikin et al. 2000), or, to a lesser degree, that of Mongolians (Fernandez-Gimenez 1999, Kakinuma et al. 2014), rural Kyrgyz' cognitive approach to pastoralism was substantially altered by the major break engendered by the Soviet "rationalization" of husbandry (Jacquesson 2010, Schmidt and Doerre 2011, Rahimon 2012). There is evidence of such an outcome elsewhere in the post-Soviet sphere, e.g., in the Republic of Georgia (Kikvidze and Tevzadze 2015).

This hypothesis is consistent with some further anecdotal evidence offered by the participants in our study. Namely, in the course of our interviews, participants often lamented a lack of medicinal plant knowledge, implying both its prior existence, and a social-service gap left by the collapse of the late Soviet state. Many participants also noted that they had turned to herding only recently, e.g., within the past decade, purely to help their families subsist. For these participants, herding was a relatively unfamiliar occupation, involving considerable guesswork, despite its iconic status as an identity marker of the Kyrgyz people (Shamsiev 2007, Steimann 2012).

The prevalence of this "forced return to herding" narrative (Liechti 2012), combined with the pattern of our results, suggests to us that many herder families may be simply emulating the land use habits they observe amongst their immediate neighbors on the landscape. This is both cognitively and energetically efficient (Levine et al. 2015), as well as one of the only ways to ensure the near-term survival of one's family given a dearth of other livelihood options. However, without a functional, well-informed, long-term approach to pasture management, we fear such a scenario is liable to devolve into a literal "tragedy of the commons" (Shamsiev 2007, Bichsel et al. 2010).

\section{CONCLUSION}

Our results constitute a tentative step in clarifying the nature of key social-ecological challenges impacting pasture management in central Kyrgyzstan. Namely, it seems local pasture users are simply bereft of much of the floristic information ecologists are using to make their assessments of land-cover change, and are instead defaulting to a set of common, but not entirely consistent, visual heuristics for determining where to graze their livestock, and when. The implication for management is that culturally sensitive knowledge-sharing, and the introduction to pasture users of new, shared, flora-centered heuristics for reading the landscape, is just as important as the collection of more data.

Given the relative participant agreement observed with respect to key indicators of "good" pasture, PMs, PCs, or academic or development experts, could first reach out to pasture users by articulating, acknowledging, and validating the mode of pasture health assessment that locals appear to be employing. Once this baseline of mutual understanding has been explicitly established, managers or outside experts could highlight the fact that there are also more slow-moving factors, and subtle floristic indicators, that, from an academic or managerial perspective, suggest when pasture may need to be rotated, despite on-the-ground appearances. A protocol for integrating these perspectives could then be established (e.g., Kassam et al. 2018). Given the enthusiastic participant engagement we observed with our methods (Activity 3, in particular), we suggest that incorporating audiovisual tools, such as video, or time-lapse visualizations, may be particularly effective in this process.

Finally, the following avenues of research may prove fruitful in the future: (a) experimentation with other audiovisual means to prime and elicit local pastoralists' tacit preferences or decisionmaking rubrics; (b) building on the consensus-analysis data presented in this paper to further identify the most important management-relevant gaps in locals' perceptions of their socialecological system; and (c) using social network analysis to trace how pastoral practices are shared in Naryn oblast and beyond. 
Responses to this article can be read online at:

http://www.ecologyandsociety.org/issues/responses. $\mathrm{php} / 11222$

\section{Acknowledgments:}

We wish to thank the Partnership for the Advancement of Human Development in Africa and Asia (AKDN and Government of Canada) for their financial support.

\section{LITERATURE CITED}

Bichsel, C., G. Fokou, A. Ibraimova, U. Kasymov, B. Steimann, and S. Thieme. 2010. Natural resource institutions in transformation: the tragedy and glory of the private. Pages 255-269 in H. Hurni and U. Wiesmann, editors. Global change and sustainable development: a synthesis of regional experiences from research partnerships. NCCR North-South, Bern, Switzerland.

Borgatti, S., M. Everett, and L. Freeman. 2002. Ucinet for Windows: software for social network analysis. Analytic Technologies, Harvard, Cambridge, Massachusetts, USA.

Carothers, C., C. Brown, K. J. Moerlein, J. López, D. B. Andersen, and B. Retherford. 2014. Measuring perceptions of climate change in northern Alaska: pairing ethnography with cultural consensus analysis. Ecology and Society 19(4):27. http://dx.doi. org/10.5751/ES-06913-190427

Crewett, W. 2012. Improving the sustainability of pasture use in Kyrgyzstan. Mountain Research and Development 32(3):267-274. https://doi.org/10.1659/MRD-JOURNAL-D-11-00128.1

Crewett, W. 2015. Introducing decentralized pasture governance in Kyrgyzstan: designing implementation rules. Environmental Science and Policy 53:215-224. https://doi.org/10.1016/j. envsci.2014.12.009

Dörre, A. 2015. Promises and realities of community-based pasture management approaches: observations from Kyrgyzstan. Pastoralism 5:15. https://doi.org/10.1186/s13570-015-0035-8

Dörre, A., and P. Borchardt. 2012. Changing systems, changing effects-pasture utilization in the post-soviet transition. Mountain Research and Development 32(3):313-323. https://doi.org/10.1659/ MRD-JOURNAL-D-11-00132.1

Eddy, I. 2016. Land degradation in Central Asia: identifying dynamics of pasture resources in heterogeneous landscapes using remote sensing Thesis. University of British Columbia, Vancouver, British Columbia, Canada.

Eddy, I. M. S., S. E. Gergel, N. C. Coops, G. M. Henebry, J. Levine, H. Zerriffi, and E. Shibkov. 2017. Integrating remote sensing and local ecological knowledge to monitor rangeland dynamics. Ecological Indicators 82:106-116. https://doi.org/10.1016/j. ecolind.2017.06.033

Ellen, R., and H. Harris. 2000. Introduction. Pages 1-34 in R. Ellen, P. Parkes, and A. Bicker, editors. Indigenous environmental knowledge and transformations. Harwood Academic, Amsterdam, The Netherlands.
Farrington, J. D. 2005. De-development in eastern Kyrgyzstan and persistence of semi-nomadic livestock herding. Nomadic Peoples 9:171-197. https://doi.org/10.3167/082279405781826191

Fernandez-Gimenez, M. 1999. Sustaining the steppes: a geographical history of pastoral land use in Mongolia. Geographical Review 89(3):315-342. https://doi.org/10.2307/216154

Flermoneca. 2015. Catalog of the pasture plants of Kyrgyzstan (In Russian). Flermonica, GIZ, Bonn, Germany. [online] URL: http://www.camp.kg/banners/6/46.html

Gan, R., Y. Luo, Q. Zuo, and L. Sun. 2015. Effects of projected climate change on the glacier and runoff generation in the Naryn River Basin, Central Asia. Journal of Hydrology 523:240-251. https://doi.org/10.1016/j.jhydrol.2015.01.057

Hamidov, A., K. Helming, and D. Balla. 2016. Impact of agricultural land use in Central Asia: a review. Agronomy for Sustainable Development 36(6):1-23. https://doi.org/10.1007/ $\underline{\text { s13593-015-0337-7 }}$

Hoppe, F., T. Zhusui Kyzy, A. Usupbaev, and U. Schickhoff. 2016. Rangeland degradation assessment in Kyrgyzstan: vegetation and soils as indicators of grazing pressure in Naryn Oblast. Journal of Mountain Science 13(9):1567-1583. https://doi.org/10.1007/ $\underline{\text { s11629-016-3915-5 }}$

Imanberdieva, N. 2015. Flora and plant formations distributed in At-Bashy Valleys - internal Tien Shan in Kyrgyzstan and interactions with climate. Pages 569-590 in M. Özturk, K. R. Hakeem, I. Faridah-Hanum, and R. Efe, editors. Climate change impacts on high-altitude ecosystems. Springer, Cham, Switzerland. https://doi.org/10.1007/978-3-319-12859-7 22

Jacquesson, S. 2010. Reforming pastoral land use in Kyrgyzstan: from clan and custom to self-government and tradition. Central Asian Survey 29(1):103-118. https://doi.org/10.1080/02634931003765571

Kakinuma, K., T. Sasaki, U. Jamsran, T. Okuro, and K. Takeuchi. 2014. Relationship between pastoralists' evaluation of rangeland state and vegetation threshold changes in Mongolian rangelands. Environmental Management 54(4):888-896. https://doi.org/10.1007/ $\underline{\mathrm{s} 00267-014-0341-8}$

Kassam, K. A. S., M. L. Ruelle, C. Samimi, A. Trabucco, and J. $\mathrm{Xu}$. 2018. Anticipating climatic variability: the potential of ecological calendars. Human Ecology 46(2):249-257. https://doi. org/10.1007/s10745-018-9970-5

Kerven, C., B. Steimann, L. Ashley, C. Dear, I. Ur-Rahim. 2011. Pastoralism and farming in Central Asia's mountains: a research review. Mountain Societies Research Institute, Bishkek, Kyrgyzstan.

Kerven, C., B. Steimann, C. Dear, and L. Ashley. 2012. Researching the future of pastoralism in Central Asia's mountains: examining development orthodoxies. Mountain Research and Development 32(3):368-377. https://doi.org/10.1659/ MRD-JOURNAL-D-12-00035.1

Kikvidze, Z., and G. Tevzadze. 2015. Loss of traditional knowledge aggravates wolf-human conflict in Georgia (Caucasus) in the wake of socio-economic change. Ambio 44(5):452-457. https://doi.org/10.1007/s13280-014-0580-1 
Klubnikin, K., C. Annett, M. Cherkasova, M. Shishin, and I. Fotieva. 2000. The sacred and the scientific: traditional ecological knowledge in Siberian river conservation. Ecological Applications 10(5):1296-1306. https://doi.org/10.1890/1051-0761(2000)010[1296: TSATST]2.0.CO:2

Kreutzmann, H. 2012. Pastoral practices in High Asia. Springer, New York, New York, USA. https://doi.org/10.1007/978-94-007-3846-1

Kulov, S. 2007. Total economic valuation of Kyrgyzstan pastoralism. International Union for Conservation of Nature (for UNDP), Naryn, Kyrgyzstan.

Levine, J., K. M. A. Chan, and T. Satterfield. 2015. From rational actor to efficient complexity manager: exorcising the ghost of Homo economicus with a unified synthesis of cognition research. Ecological Economics 114:22-32. https://doi.org/10.1016/j. ecolecon.2015.03.010

Levine, J., A. Isaeva, I. Eddy, M. Foggin, S. Gergel, S. Hagerman, and H. Zerriffi. 2017. A cognitive approach to the post-Soviet Central Asian pasture puzzle: new data from Kyrgyzstan. Regional Environmental Change 17(3):941-947. https://doi. org/10.1007/s10113-017-1122-8

Liechti, K. 2012. The meanings of pasture in resource degradation negotiations: evidence from post-socialist rural Kyrgyzstan. Mountain Research and Development 32(3):304-312. https://doi. org/10.1659/MRD-JOURNAL-D-11-00113.1

Mestre, I., A. Ibraimova, and B. Azhibekov. 2013. Conflicts over pasture resources in the Kyrgyz Republic. Central Asia Mountain Partnership (CAMP) Alatoo, Bishkek, Kyrgyzstan.

Mudahar, M. 1998. Kyrgyz Republic - strategy for rural growth and poverty alleviation. The World Bank, Washington, D.C., USA.

Ostrom, E. 1990. Governing the commons: the evolution of institutions for collective action. Cambridge University Press, Cambridge, UK.

Rahimon, R. M. 2012. Evolution of land use in pastoral culture in Central Asia with special reference to Kyrgyzstan and Kazakhstan. Pages 51-67 in V. Squires, editor. Rangeland stewardship in Central Asia: balancing improved livelihoods, biodiversity conservation and land protection. Springer, Dordrecht, The Netherlands. https://doi.org/10.1007/978-94-007-5367-9 3

Robinson, S. 2016. Land degradation in Central Asia: evidence, perception and policy. Pages 451-490 in R. H. Behnke and M. Mortimore, editors. The end of desertification? Springer, Heidelberg, Germany. https://doi.org/10.1007/978-3-642-16014-1_17

Romney, A. K., S. C. Weller, and W. H. Batchelder. 1986. Culture as consensus: a theory of culture and informant accuracy. American Anthropologist 88(2):313-338. https://doi.org/10.1525/ aa.1986.88.2.02a00020

Schmidt, M., and A. Doerre. 2011. Changing meanings of Kyrgyzstan's nut forests from colonial to post-Soviet times. Area 43(3):288-296. https://doi.org/10.1111/j.1475-4762.2010.00988.x

Shamsiev, B. 2007. Kyrgyz Republic livestock sector review: embracing the new challenges. The World Bank, Bishkek, Kyrgyzstan.
Shigaeva, J., S. Hagerman, H. Zerriffi, C. Hergarten, A. Isaeva, Z. Mamadalieva, and M. Foggin. 2016. Decentralizing governance of agropastoral systems in Kyrgyzstan: an assessment of recent pasture reforms. Mountain Research and Development 36(1):91-101. https://doi.org/10.1659/MRD-JOURNAL-D-15-00023.1

Standifer, R., and A. Bluedorn. 2006. Alliance management teams and entrainment: sharing temporal mental models. Human Relations 59(7):903-927. https://doi.org/10.1177/0018726706067596

Steimann, B. 2012. Conflicting strategies for contested resources: pastoralists' responses to uncertainty in post-socialist rural Kyrgyzstan. Pages 145-160 in H. Kreutzmann, editor. Pastoral practices in High Asia. Springer, New York, New York, USA. https://doi.org/10.1007/978-94-007-3846-1_8

Stone-Jovicich, S. S., T. Lynam, A. Leitch, and N. A. Jones. 2011. Using consensus analysis to assess mental models about water use and management in the Crocodile River catchment, South Africa. Ecology and Society 16(1):45. https://doi.org/10.5751/ES-03755-160145

University of Central Asia (UCA). 2011. Herders' manual for Kyrgyzstan. UCA, Bishkek, Kyrgyzstan. [online] URL: https:// www.ucentralasia.org/Content/Downloads/UCA_HerdersManual2011 English.pdf

Wong, J. 2018. Policy in the peaks: cybercartography and traditional ecological practices to diversify pasture policy-making in Naryn Province, Kyrgyzstan Thesis. Carleton University, Ottawa, Ontario, Canada. https://doi.org/10.22215/etd/2018-13377 